\title{
KẾT QUẢ TẠO THÔNG ĐộNG - TĨNH MẠCH ĐỂ CHẠY THậN NHÂN TẠO TẠI BỆNH VIỆN HŨUU NGHỊ VIỆT ĐỨC GIAI ĐOẠN 2016-2019
}

Sa Minh Dương*, Đoàn Quốc Hurng**

\section{TÓM TẮT}

Nhận xét kết quả sớm tạo thông động-tĩnh mạch để chạy thận nhân tạo tại bệnh viện Hữu Nghị Việt Đức. Từ 1/2016 đến 3/2019 có 51 bệnh nhân $(\mathrm{BN})$ đạt yêu cầu nghiên cứu. Tuổi trung bình $56 \pm 13$ tuổi (22-83), nam giới chiếm 55\% (28 $\mathrm{BN})$. Bệnh nhân phải chạy thận nhân tạo cấp cứu trước mổ chiếm 74,5\%. Các bệnh phối hợp: Tăng huyết áp chiếm $33,3 \%$, đái tháo đường $7,8 \%$ và một số bệnh khác như: ung thư đại tràng, phổi mạn tính...Tất cả BN trước mổ đều được siêu âm động tĩnh mạch chi trên, một số được vẽ bản đồ để đánh giá vị trí làm cầu tay. Phân bố vị trí làm cầu tay: Vùng cổ tay 49\%; khuỷu tay $45,1 \%$ và cẳng tay 5,9\%. Một số kỹ thuật đặc biệt: Nông hóa tĩnh mạch cánh tay sâu 5,6\%, chuyển vị tĩnh mạch $2 \%$. Kỹ thuật mổ: Nối tận-bên chiếm $98 \%$ và bên-bên $2 \%$. Sau mổ: Thổi rõ $90,2 \%$, thổi kém $9,2 \%$, kiểm tra siêu âm $100 \%$ cầu nối thông; không có $\mathrm{BN}$ chảy máu phải mổ lại, nhiễm trùng.

Tì khóa: Tạo thông động-tĩnh mạch, cầu tay, suy thận mạn.

\section{SUMMARY}

EARLY FOLLOW-UP RESULTS OF ARTERIOVENOUS FISTULAE CREATED FOR HEMODIALYSIS AT VIET DUC UNIVERSITY HOSPITAL PERIOD 2016-2019

Analysis early results of arterio-venous fistula created for hemodialysis - at Viet duc university hospital. From 01/2016 to 3/2019, there were 51 patients including in study. Mean age was $56 \pm 13$ years (22-83). Male was $55 \%(28) . \quad 74,5 \%$ of the patients needed emergency hemodialysis before operation.
Comorbidities were: hypertension (33,3\%), diabetes mellitus $(7,8 \%)$ and other like: colon cancer...For all the patients before surgery we did ultrasound vessel and haft of them a ultrasound vessel mapping to decide fistula location. Distribution of fistula by location was: $49 \%$ at the wrist; $45,1 \%$ at the elbow and 5,9\% at the arm. There were some special techniques: make deep brachial vein became superficial $5,6 \%$; vein translocation $2 \%$. The techniques of anastomosis between artery and vein were: end to side $(98 \%)$, side to side $(2 \%)$. Post operative Results: Clearly thrill $90,2 \%$, no serious bleeding and no infection.

Key words: Arterio-venous fistula, hemodialysis, chronic kidney failure.

\section{I. ĐẶT VẤN ĐỀ}

Phẫu thuật tạo thông động mạch-tĩnh mạch (TĐTM) là phẫu thuật để tạo ra sự thông thương trực tiếp từ động mạch (ĐM) sang tĩnh mạch (TM), có thể tạo TĐTM bằng vật liệu tổng hợp hay tạo TĐTM tự thân. Theo điều tra cắt ngang ở Trung Quốc năm 2012 tỷ lệ mắc bệnh suy thận mạn (STM) ở Trung Quốc là 10,8\% (119,5 triệu người) trong đó tỷ lệ STM là $1,7 \%[1]$. Tại bệnh viện Chợ Rẫy từ năm 2008 đến 2010 số bệnh nhân $(\mathrm{BN})$ tạo TĐTM là 2360 trong đó thành công $88,35 \%$, mổ lại là $11,65 \%$ [2]. Đã có nhiều nghiên cứu về kích thước mạch và kỹ thuật, đưa ra các lời khuyến cáo về kích

\footnotetext{
* BV Đa khoa Son La

** BV HN Việt Đức, Trưòng ĐH Y Hà Nội

Ngườ chịu trách nhiệm khoa học: PGS.TS.Đoàn Quốc Hung

Ngày nhận bài: 01/05/2019 - Ngày Cho Phép Đăng: 15/05/2019

Phản Biện Khoa học: PGS.TS. Đặng Ngọc Hùng GS.TS. Lê Ngoc Thành
} 
thước cho tỷ lệ thành công cao nhất. Vấn đề thất bại của tạo TĐTM lần đầu thường do tuổi cao, ĐTĐ, giới nữ, tiền sử bệnh mạch máu [3]. Đây là vấn đề có ý nghĩa quan trọng, thành công phẫu thuật đem lại chất lượng cuộc sống tốt cho BN vốn STM cần lọc máu.

\section{II. ĐỐI TƯợNG VÀ PHƯƠNG PHÁP NGHIÊN CÚU}

Nghiên cứu mô tả cắt ngang. Số liệu thu thập từ bệnh án của các BN STM giai đoạn cuối nhập viện, được mổ tạo TĐTM tại bệnh viện Hữu
Nghị Việt Đức từ tháng 01/2016 - 03/2019. Các yếu tố được thu thập liên quan đến $\mathrm{BN}$ như: giới, tuổi, tình trạng trước mổ, bệnh lý đi kèm, vị trí mổ, chất lượng mạch, kỹ thuật mổ, kích thước mạch trên siêu âm trước mổ và sau mổ, có chảy máu tại vị trí mổ.

\section{KẾT QUẢ}

Có 51 bệnh nhân thỏa mãn yêu cầu. Tuổi trung bình: $56 \pm 13$ tuổi (22-83 tuổi), chủ yếu BN nằm trong tuổi từ 51-70. Nam giới chiếm $55 \%$.

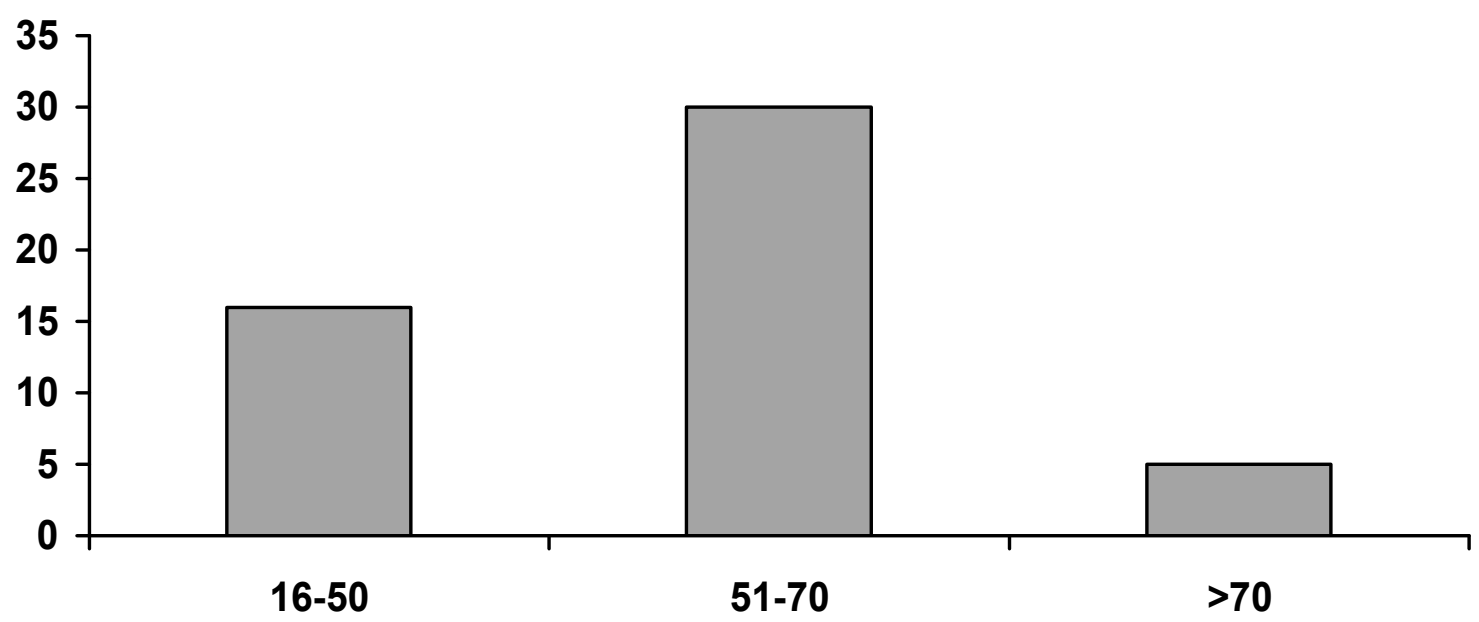

Biểu đồ 3.1: Phân bố tuổi BN nghiên cứu

Các bệnh lý kèm theo STM gồm: tăng huyết áp 33,3\%, ĐTĐ 7,8\%, bệnh tim mạch 43,1\% và một số bệnh khác như ung thư đại tràng....

Bảng 3.1: Tình trạng bệnh nhân truớc phẫu thuật $(N=51)$

\begin{tabular}{|l|c|c|}
\hline \multicolumn{1}{|c|}{ Tình trạng bệnh nhân } & n & Tỷ lệ \% \\
\hline Lọc máu cấp cứu trước, chưa có TĐTM & 38 & 74,5 \\
\hline Chưa lọc máu & 0 & 0 \\
\hline Làm lại thông động-tĩnh mạch (đã mổ trước) & $13^{*}$ & 25,5 \\
\hline Tổng cộng & 51 & 100 \\
\hline
\end{tabular}

Tất cả BN đều được siêu âm trước mổ đánh giá tình trạng mạch chi trên hai bên. Có 21 (41,2\%) được lập sơ đồ mạch máu chi trên dựa trên siêu âm trước mổ. $13^{*} \mathrm{BN}$ đã mổ làm cầu nối tại $\mathrm{BV}$ Việt Đức hoặc tại cơ sở y tế khác. 
Bảng 3.2: Kích thước trung bình mạch máu theo siêu âm được chọn phẫu thuật $(N=51)$

\begin{tabular}{|l|c|}
\hline \multicolumn{1}{|c|}{ Mạch máu } & Đường kính (mm) \\
\hline Động mạch & $3,7 \pm 1,5$ \\
\hline Tĩnh mạch & $2,6 \pm 0,6$ \\
\hline
\end{tabular}

Bảng 3.3: Vị trí phẫu thuật tạo thông động-tĩnh mạch $(N=51)$

\begin{tabular}{|c|c|c|c|}
\hline \multicolumn{2}{|c|}{ Vị Trí làm TĐTM } & $\mathbf{n}$ & Tỷ lệ \% \\
\hline \multicolumn{2}{|l|}{ Cổ tay } & 25 & 49,0 \\
\hline \multicolumn{2}{|l|}{ Cẳng tay } & 3 & 5,9 \\
\hline \multicolumn{2}{|c|}{ Khuỷu tay } & 23 & 45,1 \\
\hline \multirow[t]{2}{*}{ Đặc biệt } & Nông hóa TM & 10 & 19,6 \\
\hline & Chuyển vị TM & 1 & 2,0 \\
\hline
\end{tabular}

Vị trí tạo TĐTM tiên ưu tiên trên tay không thuận và theo thứ tự: Cổ tay (ĐM quay và TM đầu), cổ tay (ĐM trụ và TM nền), khuỷu tay. Số BN làm TĐTM tay trái/phải là 34/17 (66,7\% và 33,3\%).

Bảng 3.4: Kỹ thuật nối tạo thông động-tĩnh mạch $(N=51)$

\begin{tabular}{|l|c|c|}
\hline \multicolumn{1}{|c|}{ Kỹ thuật nối } & n & Tỷ lệ \% \\
\hline Bên - bên & 1 & 2,0 \\
\hline Tận - bên & 50 & 98,0 \\
\hline Tổng & 51 & 100 \\
\hline
\end{tabular}

Đa số BN miệng nối ĐM-TM là tận bên, chỉ có 1 BN thực hiện miệng nối ĐM-TM bên-bên. 48 $(94,1 \%)$ phẫu thuật tiến hành dưới gây tê tại chỗ

Bảng 3.5: Kết quả sau mổ tạo thông động-tĩnh mạch $(N=51)$

\begin{tabular}{|l|c|c|}
\hline \multicolumn{1}{|c|}{ Đặc điểm } & n & Tỷ lệ \% \\
\hline Tiếng thổi và rung miu rõ tại chỗ cầu nối & 42 & 82,4 \\
\hline Thấm máu tại vết mổ & 22 & 43,1 \\
\hline Siêu âm kiểm tra sau mổ cầu nối thông tốt & 51 & 100 \\
\hline
\end{tabular}

Vết mổ thấm máu gặp ở $22 \mathrm{BN}(43,1 \%)$ đều được điều trị nội khoa bảo tồn thành công.

\section{BÀN LUẬN}

$\mathrm{BN}$ trong nghiên cứu có tuổi, giới khá tương đồng với các nghiên cứu khác trong nước và nước ngoài trong đó về giới nam cao hơn nữ (28/23) (biểu đồ 1). Và tuổi thời điểm phẫu thuật trung bình là khá đồng đều >50 tuổi. Tuổi cao kèm theo nhiều bệnh mạn tính làm tăng nguy cơ phẫu thuật, thất bại do chất lượng thành ĐM và TM kém. 
Bảng 4.1: So sánh tuổi và giới của bệnh nhân với các tác giả khác

\begin{tabular}{|l|c|c|c|c|}
\hline Tác giả & Năm công bố & Cõ̃ mẫu & Tuổi & Giới (\% Nam/nữ) \\
\hline Dageforde LA[4] & 2015 & 158 & $54 \pm 14$ & $45 / 55$ \\
\hline Saucy F[5] & 2009 & 58 & $63 \pm 14,3$ & $69 / 31$ \\
\hline Sung Min Kim[6] & 2016 & 469 & $55,7 \pm 13,2$ & $62 / 38$ \\
\hline Chúng tôi & 2019 & 51 & $56 \pm 13$ & $28 / 23$ \\
\hline
\end{tabular}

Chọn lựa vị trí làm TĐTM trước mổ có ý nghĩa rất quan trọng. Theo Robbin trước phẫu thuật đường kính động mạch $>2 \mathrm{~mm}$, tĩnh mạch $>2,5 \mathrm{~mm}$ và miệng nối trong phẫu thuật $>4 \mathrm{~mm}$ tỷ lệ thành công cao hơn hẳn [7]. Chọn các TM nằm nông $(<6 \mathrm{~mm})$, TM thẳng trên 1 đoạn dài $(>6 \mathrm{~cm})$ và nằm ở trước hoặc bên thuận tiện cho chọc kim. Theo Đặng Ngọc Hùng miệng nối $8 \mathrm{~mm}$ cho những trường hợp mạch máu có đường kính nhỏ và $6 \mathrm{~mm}$ cho những trường hợp có đường kính mạch máu lớn và miệng nối thích hợp trong nối thông động-tĩnh mạch ở cổ tay, đáp ứng được yêu cầu về lưu lượng cho CTNT chu kỳ[8]. Theo Dageforde LA các thông động-tĩnh mạch có đường kính $\mathrm{TM}$ tối thiểu $<2,7 \mathrm{~mm}$ có nguy cơ thất bại trưởng thành cao hơn và độ bền ngắn hơn so với các $\mathrm{TM}$ có đường kính $\geq 3,3 \mathrm{~mm}[4]$. Đường kính $\mathrm{ĐM}$ và $\mathrm{TM}$ của chúng tôi là $3,7 \pm 1,5$ $\mathrm{mm}$ và 2,6 $\pm 0,6 \mathrm{~mm}$ tương đồng với nhiều khuyến cáo (bảng 3.2), tuy nhiên kích thước trung bình cao hơn hẳn do vị trí khuỷu tay mạch có kích thước lớn hơn cổ tay (số $\mathrm{BN}$ làm ở khuỷu là 45,1\%) (bảng 3.3), nguy cơ kích thước $\mathrm{TM}$ lớn làm lưu lượng máu cao khi trưởng thành cũng dẫn đến tăng lưu lượng máu về tim, tăng áp ĐM phổi và lưu lượng máu toàn thân bị suy yếu ở những $\mathrm{BN}$ bị suy giảm chức năng tim[9],[10]. Chúng tôi không đủ dữ liệu về kích thước miệng nối do bệnh án thiếu ghi chép.

Cần khám lâm sàng, lập bản đồ hệ thống ĐM và TM 2 tay dựa vào trên siêu âm. Đánh giá sự thông thương của hệ động mạch quay-trụ bằng Test
Allen, đo huyết áp 2 tay, độ nảy, mức độ xơ vữa... TM khám độ nổi rõ, nổi vừa, kiểm tra độ giãn nở. Tuy nhiên do là nghiên cứu hồi cứu nên dữ liệu khám ĐM và TM không được ghi chép đầy đủ trong bệnh án. Ngoài ra các $\mathrm{BN}$ có bệnh kèm theo đặc biệt là suy tim ở $\mathrm{BN}$ nghi ngờ cần làm thêm siêu âm Dopple tim, tình trạng đông máu, số lượng tiểu cầu...Theo Sung Min Kim giới nữ và có đái tháo đường là yếu tố liên quan đến thất bại ở mổ TĐTM lần đầu $(\mathrm{P}=0,001$ và $\mathrm{P}=0,006)[6]$.

Về thời điểm mổ tạo TĐTM đa số các tác giả đều thống nhất nên mổ làm từ 6 tháng đến 1 năm trước lọc máu lần đầu (từ giai đoạn IIIb) để lỗ thông phát triển tốt với $\mathrm{BN}$ có ĐTĐ thì cần làm sớm hơn, ở đây thực tế $\mathrm{BN}$ đa số là chạy thận cấp cứu trước mổ chiếm khá cao $(74,5 \%)$ đến viện khi creatinin tăng rất cao nên việc tiêm truyền vào tĩnh mạch nông làm hỏng mạch máu khiến lựa chọn khó khăn TM để mổ. Số BN bị hỏng TĐTM mổ lại chiếm 25,5\%, việc mổ lại lựa chọn mạch máu phù hợp càng khó khăn và phải áp dụng thêm các kỹ thuật đặc biệt gây tốn kém, thời gian chờ sử dụng TĐTM và chất lượng cuộc sống $\mathrm{BN}$.

Đánh giá trên siêu âm và vẽ sơ đồ mạch máu chi trên rất có giá trị gợi ý hỗ trợ cho chọn lựa mạch máu tốt để làm TĐTM và có sự chuẩn bị trong trường hợp khó chọn mạch để có phương án khác và tư vấn cho $\mathrm{BN}$. Ở đây tất cả $\mathrm{BN}$ đều được siêu âm trước mổ tuy nhiên chỉ có 21 $(41,2 \%)$ trường hợp được lập sơ đồ mạch máu tuy nhiên các năm trở lại đây đều được lập sơ đồ mạch máu trước mổ. Theo Wong CS khám lâm 
sàng kết hợp lập bản đồ mạch trước mổ dựa vào siêu âm cho kết quả tích cực hơn (174 thành công/214 kết hợp siêu âm so với 130 thành công/188 chỉ khám lâm sàng)[11].

Chọn vị trí ưu tiên từ xa đến gần để tránh các biến chứng và nếu TĐTM hỏng còn nhiều lựa chọn vị trí khác. Bệnh viện Việt Đức là tuyến cuối nên chúng tôi nhận nhiều các trường hợp đã làm cầu nối ĐT-TM ở các cơ sở khác thất bại. Do vậy tỷ lệ $\mathrm{BN}$ làm lại TĐTM cao $(25,5 \%)$, cần làm lại nhiều nên vị trí làm tại khuỷu tay khá cao: $23(45,1 \%)$ ca, các lần mổ đầu lựa chọn vị trí cổ tay 25 ca: $(49,0 \%)$ còn $3 \mathrm{ca}(5,9 \%)$ ở cẳng tay do TĐTM hỏng do tắc và phình nên thắt, cắt bỏ đoạn cũ và được nối lại luôn ngay trên cẳng tay do đoạn khả dụng còn đủ và $\mathrm{TM}$ còn ở nông $(<6 \mathrm{~mm})$.

Chỉ chọn tay thuận khi tay không thuận không đủ khả năng làm hoặc đã mổ trước đó. Ở đây số $\mathrm{BN}$ tay trái/phải là 34/17 tỷ lệ tương ứng $66,7 \%$ và $33,3 \%$ vì số TĐTM bị hỏng phải làm lại nên tỷ lệ phẫu thuật trên tay thuận cao.

Trong các kỹ thuật mổ có một số kỹ thuật đặc biệt (bảng 3):

+Nông hóa TM: Số BN được làm tại vị trí khuỷu do TM nền và đầu hẹp nhỏ không đủ khả năng làm nên sử dụng TM cánh tay ở sâu nên được làm nông hóa TM là 10 ca $(19,6 \%)$.

+Chuyển vị TM: Có 1 ca hỏng TĐTM tay trái chuyển sang cổ tay phải được làm bằng ĐM trụ và $\mathrm{TM}$ nền được chuyển vị TM $(2,0 \%)$.

Kỹ thuật nối (bảng 3.4): Tăng áp lực tĩnh mạch bàn tay xuất hiện khá thường xuyên nếu miệng nối được thực hiện bởi kỹ thuật bên-bên nên đa số kỹ thuật khâu là tận-bên chiếm $98,0 \%$ và có 1 $\mathrm{BN}$ là bên bên $(2,0 \%)$. Theo Moini kỹ thuật nối bên-bên với vị trí khuỷu tay kèm phá van TM quanh đó khi các TĐTM trước đó đã tắc hỏng cho kết quả $82 \%$ còn tốt sau 1 năm, biến chứng tăng áp lực TM và thiếu máu chi là hiếm[12] ở đây kỹ thuật còn mới chưa được sử dụng.

\section{Phương pháp vô cảm}

Tùy vào vị trí, thời gian mổ kéo dài và đường mổ mà có lựa chọn vô cảm cho phù hợp, ở đây đa số chọn tê tại chỗ $(94,1 \%)$ để hạn chế lượng thuốc vào do thận đã mất chức năng thải, và có $3 \mathrm{BN}(5,9 \%)$ thực hiện dưới tê đám rối thần kinh cánh tay do phẫu thuật lại, khó, đường mổ rộng, thời gian mổ kéo dài. Tuy nhiên xu hướng trên thế giới hiện nay là cần thực hiện phẫu thuật này dưới gây tê đám rối thần kinh vì nhiều ưu điểm: hiệu quả vô cảm tốt, có thể mở rộng đường mổ nếu cần, không làm biến đổi giải phẫu tại chỗ (phù nề do thuốc gây tê, làm khó cho phẫu tích), và thuốc gây tê đám rối có tác dụng làm giãn ĐM và TM ngoại vi.

\section{Kết quả sau mổ (bảng 3.5)}

Sau mổ được thăm khám lâm sàng và đánh giá bằng siêu âm tại chỗ. Ở đây số ca thổi rõ ngay sau mổ là $42 / 51$ chiếm $82,4 \%$ còn lại là thổi kém nguyên nhân thường $\mathrm{BN}$ có thành cả $\mathrm{DM}$ và $\mathrm{TM}$ chất lượng kém. Siêu âm sau mổ kiểm tra hệ thống là cần thiết, để sớm phát hiện các biến chứng hẹp tắc cầu nối, huyết khối. Nếu có cần can thiệp lại sớm (lấy huyết khối, nong miệng nối, mổ lại khi do lỗi kỹ thuật..). Chúng tôi không có $\mathrm{BN}$ nào có biến chứng này, chứng tỏ kỹ thuật làm TĐTM tại BV Việt Đức là tốt. Do suy thận, dùng Heparin nên có tỷ lệ nhất định $(43,1 \%)$ máu thấm băng tại vết mổ, nhưng chỉ cần điều trị băng ép, điều chỉnh đông máu. Không $\mathrm{BN}$ nào phải mổ lại (bảng 3.5).

\section{Một số vấn đề khác}

Đường mổ vừa phải $(3-5 \mathrm{~cm})$, bóc tách mạch máu nhẹ nhàng, tránh gây tổn thương thành mạch (vốn đã không tốt do quá trình bệnh mạn 
tính). Bóc lớp giao cảm quanh ĐM để tránh co thắt...Sử dụng huyết thanh Natri Clorua $9 \%$ pha Heparin trong mổ tưới rửa các mạch máu trong quá trình làm miệng nối. Nên dùng kính phóng đại, kim chỉ mạch máu 7/0, 8/0, dụng cụ không chấn thương...là những yếu tố quan trọng ảnh hưởng tới kết quả sớm và lâu dài.

\section{KẾT LUẬN}

Nghiên cứu $51 \mathrm{BN}$ làm thông động-tĩnh mạch trong suy thận mạn tại Bệnh viện HN Việt Đức cho kết quả sớm tốt, tỷ lệ tai biến, biến chứng thấp. Việc lựa chọn vị trí tạo TĐTM có ý nghĩa quan trọng làm tăng khả năng thành công của phẫu thuật, cũng như lưu ý tới các đánh giá trước mổ, kỹ thuật trong mổ, theo dõi sát sau mổ (lâm sàng, siêu âm)..là cần thiết. Trong tương lai sẽ cần tiếp tục nghiên cứu hiệu quả thực hiện phẫu thuật dưới gây tê vùng và đánh giá kết quả lâu dài nhóm bệnh nhân này.

\section{TÀI LIỆU THAM KHẢO}

1. Zhang Luxia, Wang Fang and Wang Li (2012). Prevalanve of chronic kidney disease in china: A cross-sectional survey. The Lancet, 379 (9818), 815-822.

2. Thái Minh Sâm, Dương Quang Vũ và Châu Quý Thuận (2011). Phẫu thuật tạo dò động tĩnh mạch để chạy thận nhân tạo. Hội Nghị Khoa Học Kỹy Thuật Bệnh viện Chơ Rẫy, 15 (4), 561-565.

3. Michelle L. Robbin, Tom Greene, Alfred K. Cheung el at (2016). Arteriovenous Fistula Development in the First 6 Weeks after Creation. Radiology, 279 (2), 620-629.

4. Dageforde LA, Harms KA, Feurer ID el at (2015). Increased minimum vein diameter on preoperative mapping with duplex ultrasound is associated with arteriovenous fistula maturation and secondary patency. J Vasc Surg, 61 (1), 170-176.

5. F. Saucy, Claude Haesler E Fau - Haller, Sebastien Haller C Fau - Deglise el at (2009). Is intra-operative blood flow predictive for early failure of radiocephalic arteriovenous fistula? Nephrol Dial Transplant, 10, 1093- 1096.

6. Sung Min Kim, Youngjin Han, Hyunwook Kwon el at (2016). Impact of a preoperative evaluation on the outcomes of an arteriovenous fistula. Ann Surg Treat Res, 90 (4), 224-230.

7. Robbin M. L, Chamberlain NE, Lockhart $\mathrm{ME}$ el at (2002). Hemodialysis arteriovenous fistula maturity: US evaluation. Radiology, 225, 59- 64.

8. Đặng Ngọc Hùng, Nguyễn Tất Thắng và Nguyễn Sanh Tùng (2009). Kích thước miệng nối và lưu lượng trở về trong nối thông động - tĩnh mạch ở cổ tay để chạy thận nhân tạo chu kỳ. $Y$ họ thưc hành, 12 (694), 22-27.

9. R. Amerling, C. Ronco, M. Kuhlman el at (2011). Arteriovenous fistula toxicity. Blood Purif, 31 (1-3), 113-120.

10. B. M. Voorzaat, J. van Schaik, H. M. Siebelink el at (2016). The pros and cons of preserving a functioning arteriovenous fistula after kidney transplantation. J Vasc Access, 17 (1), 16-22.

11. Wong Chee Siong, McNicholas Nuala, Healy Donagh el at (2013). A systematic review of preoperative duplex ultrasonography and arteriovenous fistula formation. Journal of Vascular Surgery, 57 (4), 1129-1133.

12. Majid Moini, G. Melville Williams, Mohammad Sadegh Pourabbasi el at (2008). Side-to-side arteriovenous fistula at the elbow with perforating vein ligation. Journal of Vascular Surgery, 47 (6), 1274-1278. 